\title{
Structure and Function of PICK1
}

\author{
Junyu Xu Jun Xia \\ Department of Biochemistry, The Hong Kong University of Science and Technology, Kowloon, \\ Hong Kong, SAR, China
}

\section{Key Words}

PICK1 • PDZ domain • BAR domain • Protein trafficking •

AMPA receptor $\cdot$ Long-term potentiation $\cdot$ Long-term

depression · Synaptic plasticity • Lipid binding •

Phosphoinositides

\begin{abstract}
PICK1 is a peripheral membrane protein conserved from Caenorhabditis elegans to the human. It is expressed in many tissues with high levels in brain and testis. Inside cells, PICK1 is localized at the perinuclear region as well as specialized structures such as synapses of neurons. PICK1 contains a PDZ domain and a BAR domain. The PDZ domain of PICK1 binds to a large number of membrane proteins, especially proteins with C-terminal type II PDZ-binding motifs. The BAR domain of PICK1 binds to lipid molecules, mainly phosphoinositides. While the PDZ domain and the linker region of PICK1 enhance BAR domain's lipid binding, the C-terminal region of PICK1 inhibits its lipid binding. PICK1 regulates the subcellular localization and surface expression of its PDZ-binding partners. Lipid binding of PICK1's BAR domain is important for this regulation. With its PDZ domain interacting with membrane proteins and its BAR domain binding to lipids, the unique structure of PICK1 enables it to couple membrane proteins to protein-trafficking machinery.
\end{abstract}

Copyright $\odot 2007$ S. Karger AG, Base
(C) 2007 S. Karger AG, Basel

$1424-862 \mathrm{X} / 07 / 0154-0190 \$ 23.50 / 0$

Fax +41613061234 E-Mail karger@karger.ch www.karger.com

\section{Overview}

PICK1 (protein that interacts with C kinase 1) is a peripheral membrane protein initially cloned as one of the proteins interacting with protein kinase $\mathrm{C}-\alpha(\mathrm{PKC} \alpha)$ from a yeast two-hybrid screening [1]. PICK1 exists in many animal species and is conserved all the way from Caenorhabditis elegans to humans. In fact, database analysis indicates that all of the animal species with full genome sequenced to date have PICK1. However, PICK1 has not been found in unicellular organisms such as yeast or bacteria, suggesting it may not be an essential gene for cell survival. This is supported by the finding that PICK1 knockout mice are viable $[2,3]$. Surprisingly, we did not find anything close to PICK1 in plants from a database search. This suggests that PICK1 could be involved in functions unique to animals.

PICK1 was found to be expressed in many tissues [1, 4]. In immunoblot analysis using rat tissue homogenates, PICK1 was recognized as a band around $55 \mathrm{kDa}$, with the highest expression found in the brain, followed by testis [4]. A modest level of PICK1 was found in heart, lung, liver, spleen, kidney and muscle. Developmentally, PICK1 can be detected from rat brain as early as embryonic day 15 [4]. It gradually increases and reaches a plateau around 2 weeks after birth. In most cells, PICK1 was found to diffuse in the cytosol with a certain enrichment around the perinuclear region $[1,4-9]$, but it was also reported that PICK1 can be detected on mitochondria in NIH 3T3 cells [10]. In neurons, PICK1 was found to localize at syn- 
apses, a specialized structure mediating neuronal communication $[4,5]$.

PICK1 protein is made of over 400 amino acid residues, ranging from 405 residues in Xenopus, 415 in humans to 504 in Drosophila (fig. 1). It contains two structurally known domains, a PDZ (PSD-95/Dlg/ZO-1) domain with about 90 amino acid residues close to its $\mathrm{N}$-terminus, and a larger BAR (Bin/amphiphysin/Rvs) domain with about 200 residues spanning half of the protein (fig. 1). In addition, there are three regions that border these two domains: a short $\mathrm{N}$-terminal region of $\sim 18$ residues before the PDZ domain enriched with acidic residues, a linker region of $\sim 40$ residues between the PDZ and BAR domains, and a C-terminal region characterized with a stretch of acidic residues. The two domains and three regions are conserved all the way from C. elegans to humans (fig. 1). The $\mathrm{C}$-terminal region is the most divergent across species. The $\mathrm{C}$-terminal region is about 60 amino acids long in most species, except in $C$. elegans and Drosophila, which have about 90 and 140 residues, respectively. Despite the diversity, the C-terminal regions from all species possess a common feature, which is a stretch of acidic amino acid residues. The domain structure of PICK1 is rather unique. There is no other gene in the NCBI database that has a similar structure. In fact, PICK1 is the only known gene which possesses both a PDZ domain and a BAR domain in the database.

\section{PICK1 PDZ Domain Is a Protein-Protein Interaction Module}

PDZ domains are well-characterized protein-protein interaction modules [11]. They normally consist of $80-$ 100 amino acid residues that form six anti-parallel $\beta$ strands ( $\beta \mathrm{A}-\beta \mathrm{F})$ and two $\alpha$-helices $(\alpha \mathrm{A}$ and $\alpha \mathrm{B})$ (fig. 2 ). The $\beta B$ strand and $\alpha B$ helix form the binding pocket to PDZ-binding motifs. The classical PDZ-binding motifs are short peptides located at the extreme C-termini of proteins. An internal sequence that forms a hairpin-like structure mimicking the C-terminal peptide could also bind to the binding pocket [11]. In addition, the PDZ domain is capable of forming a dimer with the other PDZ domain [12]. More recently, the PDZ domain has been reported to bind to lipid molecules, such as phosphoinositides [13].

PDZ domains can be divided into three types, based on their selectivity on PDZ-binding motifs [11]. These types were mainly determined by the residue located at the -2 position of the PDZ-binding motif (the last amino acid at the $\mathrm{C}$-terminus was set as the 0 position). The type I PDZ domain recognizes -X-T/S-X- $\Phi$, where $\mathrm{X}$ stands for any residues and $\Phi$ stands for hydrophobic residues. The type II PDZ domain recognizes $-\mathrm{X}-\Phi-\mathrm{X}-\Phi$ and the type III PDZ domain recognizes -X-D/E-X- $\Phi$. The selectivity to different types of PDZ-binding motifs is determined by the first residue of $\alpha$-helix B ( $\alpha \mathrm{B} 1)$ of the PDZ domain. In the type I PDZ domain, $\alpha \mathrm{B} 1$ is a histidine, whose N3 nitrogen bond forms hydrogen bond with the hydroxyl group of the serine or threonine at the -2 position of PDZbinding motifs. In the type II PDZ domain, the $\alpha \mathrm{B} 1$ is usually a hydrophobic residue, which accommodates the hydrophobic residue at -2 position. The $\alpha \mathrm{B} 1$ positions of type III PDZ domains were usually a tyrosine, whose hydroxyl group coordinates the carboxyl group of acidic residues $[14,15]$.

The PDZ domain was found to function in regulating subcellular targeting of proteins, especially membrane proteins. For example, the prototypical PDZ domain containing protein PSD-95 is highly enriched at synapses and believed to be responsible for bringing and regulating glutamate receptors at synapses [16]. Another important function of the PDZ domain is to serve as protein scaffolds for assembly of multimeric protein complexes. PDZ domains are often found to form tandem repeats. This arrangement will enable the PDZ domain-containing protein to bring different proteins together to form complexes. For example, InaD has five PDZ domains that bring different components of phototransduction cascade together to form a signaling complex [17]. In addition to tandem repeats, the PDZ domain could also team up with other protein interaction modules, such as SH3 and GK domains to assemble protein complexes [11].

PICK1 has a single PDZ domain. The crystal structure of the human PICK1 PDZ domain was recently resolved (unpublished structure in NCBI database). Similar to other PDZ domain proteins, PICK1's PDZ domain also consists of six $\beta$ sheets and two $\alpha$ helixes with $\alpha B$ and $\beta B$ forming the binding pocket (fig. 2). Lysine 27 of PICK1 (unless otherwise specified, the residue numbers of PICK1 in this article refer to human, rat or mouse PICK1 sequence, which differ only in one position in the C-terminal acidic region) at the loop between $\beta A$ and $\beta B$ sheet forms the bottom of the pocket, with its positively charged side chain coordinates the carboxyl group of the C-terminus. Mutation of K27 together with the nearby D28 will completely disrupt PICK1's PDZ interaction [4, 18]. In the critical $\alpha \mathrm{B} 1$ position, which determines the types of PDZ domain, PICK1 has a lysine (K83) (fig. 2). This 
NAR

Linker

CAR

b

Human

Rat

Mouse

Xenopus

Sea.urchin

Drosophila

C.elegans

Human

Rat

Mouse

Xenopus

Sea.urchin

Drosophila

C.elegans

Human

Rat

Mouse

Xenopus

Sea.urchin

Drosophila

C.elegans

Human

Rat

Mouse

Xenopus

Sea.urchin

Drosophila

C.elegans

Fig. 1. Domain structure and sequence alignment of PICK1 protein. a Diagram of PICK1 domains showing the N-terminal acidic region (NAR), PDZ domain, linker region, BAR domain and the $\mathrm{C}$-terminal acidic region (CAR). b Protein sequence alignment of PICK1 from different species. The alignment was generated by CLUSTW with slight modification. Sequences used in the alignment are: Human NP_036539, Rat NP_445912, Mouse NP_ 032863, Xenopus AAI08637, Sea urchin XP_788322, Drosophila NP_609582, and C. elegans NP_502796. The border of the PDZ domain was set based on a recent crystal structure of human PICK1 deposited in the NCBI database. The borders of the BAR domain were set based on secondary structure analysis and sequence alignment with arfaptin and amphiphysin BAR domains, whose structures had been determined by crystallography. All amino acid residue positions on the top row refer to the human sequence.

Human

Rat

Mouse

Xenopus

Sea.urchin

Drosophila

C.elegans

Human

Rat

Mouse

Xenopus

Sea.urchin

Drosophila

C.elegans

Human

Haman

Rat

Mouse

Xenopus
Sea.urchin

Sea.urchin
Drosophila

C.elegans

Drosophila

C.elegans

Drosophila

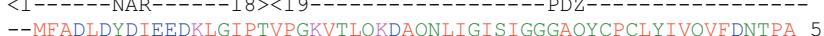

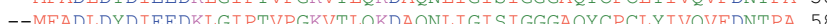
- MFADIDYDIEEDKTGIPTVPGKTTL --MESDLDYDYEEDKLGIPTVPGTVTLKKDSQNVIGISIGGGAQHCPCLYIVQVEDNTPA 58 ----MDFELEEDRMGMEAIPGTAKLVKDSQNLVGISIGGGAPLCPCLYIVQVEDNTPA 54 MLTDTEDDFFEEEDKMGMTVSTNAVVITKDQSNLIGISIGGGAPMCPCLYIVQIFDGTPA 60 -----MDEQIEEDRLGMRI QSETIELTKDEKGVVGISIGGGGPYCPCVYVVQVEDKSPA 54 ${ }^{*}: * * *::^{*}: \quad: * * \ldots::^{* * * * * *}, *^{* *}:{ }^{*}{ }^{* *}:{ }^{* *}:{ }^{* *}$

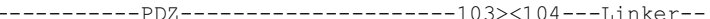
ALDGTVAAGDEITGVNGRS IKGKTKVEVAKMIOEVKGEVTIHYNKLQADPKOGMSLDIVL 118 ALDGTVAAGDEITGVNGRS IKGKTKVEVAKMIQEVKGEVTI HYNKLQADPKQGMS LDIVL 118 ALDGTVAAGDEITGVNGKSIKGKTKVEVAKMIQEVKGEVTIHYNKLQADPKQGMSLDIVL 118 ALDGTIAAGDEITGVNSKSVKGKTKVEVAKMIQNVKGEVIIHYNKLQADPKQGKS LDIVL 118 AKSKLLNAGDEIVGVNKKSVKGRTKVEVARMIQALKSEVIISYNSLKADTKEGKGLDIAL 114 AREGSLQSGDELLAVNSVSVKGKTKVEVAKMIQTATDEVVIHYNKLHADPEQGKTLDIIL 120 FKDGRIRCGDEIVAINGITVKGERKSAVAQLIQVSLNPVKITINKLEEANTKGKTLDILI 114

$$
: .^{* *}::^{*}::^{* *}, *^{* *}::^{* *}, *^{*} *^{*},{ }^{*}, *^{* * *}:
$$

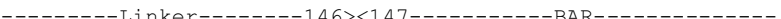

KKVKHRLVENMS SGTADALGLSRAILCNDGLVKRLEELERTAELYKGMTEHTKNLLRAFY 178 KKVKHRLVENMS SGTADALGLSRAILCNDGLVKRLEEIERTAELYKGMTEHTKNLLRAFY 178 KKVKHRLVENMS SGTADALGLSRA ILCNDGLVKRLEELERTAELYKGMTEHTKNLIRAFY 178 KKVKHRLVENMS SGAADALGLSRA ILCNDGLVKKLEELEKTGEFYRGMMEHTKRLIRAFF 178 KKAKHRMVENLSSSTADALGISRAILCNDVLTKRLDELNKTSRLYKGLMDHTKKLTKTFY 174

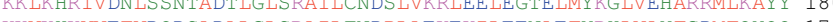
KKVKHKVEFVDQDSADALGLSRAILTNDPLAEKEKILEENAEFYRHLVAYGDMFQYQQ 174 ${ }^{* *}{ }^{* *}::^{*}: \quad: \ldots:^{* *}:{ }^{* * * * * * *}{ }^{* *}{ }^{*}::{ }^{*}: \quad:^{*}: \quad: \quad: \quad::$

ELSQTHRAFGDVFSVIGVREPQPAASEAFVKFADAHRSIEKFGIRLLKTIKPMLTDLNTY 238 ELSQTHRAFGDVFSVIGVREPQPAASEAFVKFADAHRSIEKFGIRLLKTIKPMLTDLNTY 238 DVSOTHRAFGDVFSVTGVRDAOPAASEAFVKFADAHRSTEKFGTRITKTTKPMTTDLNTY 238 238 ELSTRRA GDIECLIGAREIOPKASDAETKEGDARIUEKGIRLLRTVKPULSDLGIE 238

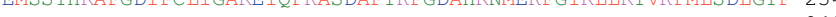
DLLQTYKSFGDCF'TQISVHEPQQRASEAFRTEGEFHRTLEKDGLGIIKQIKPVLADLGTY 240 KISECQKEFGSIFCDLAAHEKQQTANEAFSSFGDKHRMIAKKQSESAVPLQKMVSDLQVY 234

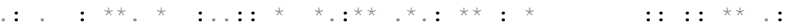

TNKATPDTRITTKKYLDVKFEYLSYCLKVKEMDDEEYSCTALGEPLYRVSTGNYEYRIIL 298 LNKAIPDTRLTIKKYLDVKEEYLSYCLKVKEMDDEEYSCIALGEPLYRVSTGNYEYRLIL 298 LNKAIPDTRLTIKKYLDVKFEYLSYCLKVKEMDDEEYSCIAARRALYRVSTGNYEYRLIL 298 LNKAIPDTRLTIRKYLDVKEEYLSYCLKVKEMDDEEYSSIALGEPLYRVGTGNYEYRLIL 298 LTKAIPDTKLTIKKYADTKEEYLSYCLKVKEMDDEEYAYATLGEPLYRVETGNYEYRLIL 294 LNKAIPDTKLTVRRYADAKFTYLSYCLKVKEMDDEEHGFAALQEPLYRVETGNYEYRLIL 300 IDHVVPDTRITTKKYTDVKYEYISYCTKTKEMDDEEVEFVATOEPLYRVETGNYEYRVMT 294

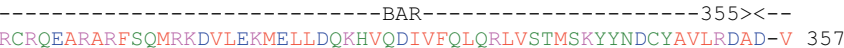
RCRQEARARFSQMRKDVLEKMELIDQKHVQDIVEQLQRFVSTMSKYYNDCYAVLRDAD-V 357 RCRQEARARESQMRKDVLEKMELLDQKHVQDIVFQLQREVSTMSKYYNDCYAVLQDAD-V 357 RCRQEARTRFAKMRKDVLEKIELLDQKHVQDIVEQLQREVSTMSKYNDQCYAVLKEAD-I 357 RCROFARARFAKTRSDVMYZYMETIDOKHVODTVEOTHRTVSAMTOYTODCHOQMKNTD-I 353 CRODARSKEAKLRTDVEKMELLECKHMDLUKORSTIEST RCRQECRARFMKMRDDVMVKIELLDQKHVRDIAQHLAIFAKTMAKCQQECAEILKERI-D 353 ${ }^{* * * *}:{ }^{*}::^{*}::{ }^{*}{ }^{*}:{ }^{*}:{ }^{* *}:{ }^{* *},{ }^{*}: \quad:{ }^{*}:$ : $:::: \quad . \quad:$

356---n-FPIEVDLAHTTLAYGLNQEEFTDGEEEEEEED-TAAGEPSRDTRGAAGPLDKGGSWCDS* 415 EPIEVDLAHTTLAYGPNQGGETDGEDEEEEEEDGAAREVSKDARGATGPTDKGGSWCDS* 416 FPIEVDLAHTTLAYGPNOGSFTDGEEEDEEEEDGAAREVSKDACGATGPTDKGGSWCDS * 416 EPIEVDLAKTTLACGQGE-TFTDGTDEEEEDO----TEKRKEEENGEKLIDDA* 405 FPIEVDLLRTTINYDRSD-QFNDGEDDEEEEEEEEEEEEEENNRGGGGGSLMEGNLIDTS* 412 EPIEVDEKETDFQYKSSTLKPQEL-DDDEIEANNHPHSTPSQVDCGEEAVEQPAAIINVE 419 VPIEIDLEQLNLNMNTSDGKANG--EEEMGQDAIVLNDNPLEGDLIDVNDIGSSTEFNEP 411 ${ }^{* * *}:{ }^{*}: \quad: \quad::: \quad:$

AAKASVDSSTLOSASENETLIKELGLYDVDLISNPOTISNOKDSIAAONDGYDFDLFLNO 479

RISLRRDSQNDTSQPLIGAPDSPLEELSLIDIS*
504 

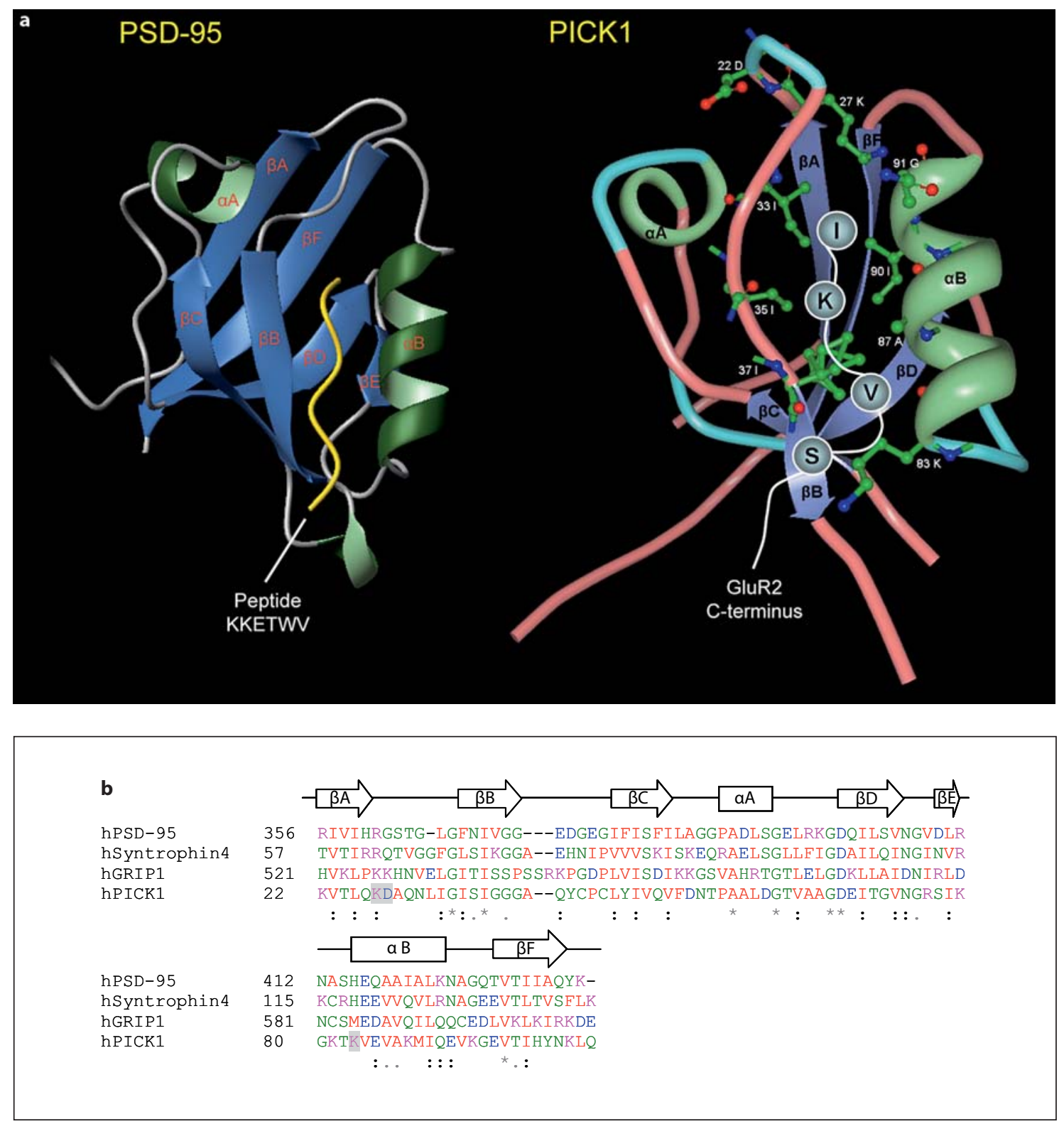

Fig. 2. The PDZ domain of PICK1. a Ribbon diagram of PDZ domains: the third PDZ domain of PSD-95 in a complex with a binding peptide KKETWV, and the PDZ domain of PICK1. Residues with a side chain pointing to the binding pocket of the PICK1 PDZ domain were shown together with the last four amino acid residues of the GluR2 C-terminus to illustrate the binding. The diagrams were generated by Molmol and Protein Workshop using the structure files 1TP5 and 2GZV from the PDB database. b Pro- tein sequence alignment of PDZ domains from different human proteins: the third PDZ domain of PSD-95 (NP_001356), PDZ domain of syntrophin 4 (NP_061840), the fifth PDZ domain of GRIP1 that is responsible for binding to GluR2-C (NP_066973) and the PDZdomain of PICK1 (NP_001034672). Residues K27D28 of PICK1, which are critical for binding to PDZ ligands, and residue $\mathrm{K} 83$, which determines the preference to different types of PDZ-binding motifs, are highlighted. makes the PICK1 PDZ domain rather unique and cannot be easily classified as either type I, type II or type III. In fact, the PDZ domain of PICK1 was found to interact with both type I and type II PDZ-binding motifs (table 1).
To date, over 40 proteins have been identified to interact with PICK1 (table 1). Most of these proteins are membrane proteins, including receptors, transporters and ionic channels. These proteins have diverse functions, 
Table 1. Classification of PICK1 PDZ domain interacting proteins

\begin{tabular}{|c|c|c|c|c|c|}
\hline PICK1 interacting protein & $\begin{array}{l}\text { Binding } \\
\text { sequence }\end{array}$ & $\begin{array}{l}\text { Detection } \\
\text { approach }\end{array}$ & $\begin{array}{l}\text { Co- } \\
\text { cluster }\end{array}$ & $\begin{array}{l}\text { Surface } \\
\text { change }\end{array}$ & Ref. \\
\hline \multicolumn{6}{|l|}{ Type I: -X-S/T-X- $\Phi$} \\
\hline Aquaporin 2, water channel & LPRGSKA & $\mathrm{Y} 2 \mathrm{H}$ & ND & ND & 58 \\
\hline CAR, coxsackievirus and adenovirus receptor & SKDGSIV & In vitro & Yes & ND & 59 \\
\hline ERBB4, receptor tyrosine-protein kinase & RHRNTVV & $\mathrm{Y} 2 \mathrm{H}$ & ND & ND & 8 \\
\hline GluR5, kainate receptor & QRKETVA & $\mathrm{Y} 2 \mathrm{H}$, in vitro & ND & ND & 60 \\
\hline GluR6, kainate receptor & PGKETMA & $\mathrm{Y} 2 \mathrm{H}$, in vitro & ND & ND & 60 \\
\hline Kalirin-7, neuronal Rho-GEF & DPFSTYV & $\mathrm{Y} 2 \mathrm{H}$ & ND & $\mathrm{N} / \mathrm{A}$ & 61 \\
\hline mGluR8b, metabotropic glutamate receptor & VKSGSTS & $\mathrm{Y} 2 \mathrm{H}$ & ND & ND & 62 \\
\hline Neuroligin 1 & SHSTTRV & $\mathrm{Y} 2 \mathrm{H}$ & ND & ND & 63 \\
\hline Neuroligin 2 & PHSTTRV & $\mathrm{Y} 2 \mathrm{H}$ & ND & ND & 63 \\
\hline$P K C a$ & PILQSAV & $\mathrm{Y} 2 \mathrm{H}$, in vitro & No & $\mathrm{N} / \mathrm{A}$ & 1,18 \\
\hline \multicolumn{6}{|l|}{ Type II: -X- $\Phi-X-\Phi$} \\
\hline Anionic exchanger 1 & DEVAMPV & $\mathrm{Y} 2 \mathrm{H}$ & ND & ND & 58 \\
\hline Anionic exchanger 2 & NEMPMPV & $\mathrm{Y} 2 \mathrm{H}$ & ND & ND & 58 \\
\hline Aquaporin 9 , water channel & HELSVIM & $\mathrm{Y} 2 \mathrm{H}$ & ND & ND & 58 \\
\hline ASIC1, acid-sensing ion channel & TFEEIAC & $\mathrm{Y} 2 \mathrm{H}$, in vitro & Yes & ND & $64-66$ \\
\hline ASIC2, acid-sensing ion channel & TFEDFTC & $\mathrm{Y} 2 \mathrm{H}$, in vitro & Yes & ND & 64,65 \\
\hline DAT, dopamine transporter & LRHWLKV & $\mathrm{Y} 2 \mathrm{H}$, in vitro & Yes & Yes & 6 \\
\hline EphA7, ephrin receptor & HGTGIQV & $\mathrm{Y} 2 \mathrm{H}$, in vitro & ND & ND & 7 \\
\hline EphB2, ephrin receptor & QIQSVEV & $\mathrm{Y} 2 \mathrm{H}$, in vitro, in vivo & Yes & ND & 7 \\
\hline Ephrin B1 & ANIYYKV & $\mathrm{Y} 2 \mathrm{H}$, in vitro & Yes & ND & 7 \\
\hline ERBB2, receptor tyrosine-protein kinase & LGLDVPV & $\mathrm{Y} 2 \mathrm{H}$, in vitro & ND & ND & 8 \\
\hline GluR2, AMPA receptor subunit & GIESVKI & $\mathrm{Y} 2 \mathrm{H}$, in vitro, in vivo & Yes & Yes & 4,35 \\
\hline GluR3, AMPA receptor subunit & GTESVKI & $\mathrm{Y} 2 \mathrm{H}$ & ND & ND & 4,35 \\
\hline GluR4c, AMPA receptor subunit & GTESIKI & $\mathrm{Y} 2 \mathrm{H}$ & ND & ND & 4,35 \\
\hline JAM-A, junctional adhesion molecule & QTSSFLV & $\mathrm{Y} 2 \mathrm{H}$, in vitro & ND & ND & 67 \\
\hline JAM-B, junctional adhesion molecule & HTKSFII & $\mathrm{Y} 2 \mathrm{H}$ & ND & ND & 67 \\
\hline JAM-C, junctional adhesion molecule & HKSSFVI & $\mathrm{Y} 2 \mathrm{H}$, in vitro & ND & ND & 67 \\
\hline mGluR7a, metabotropic glutamate receptor & SYNNLVI & $\mathrm{Y} 2 \mathrm{H}$, in vitro, in vivo & Yes & No & $62,68,69$ \\
\hline mGluR7b, metabotropic glutamate receptor & YTIPPTV & $\mathrm{Y} 2 \mathrm{H}$, in vitro & ND & ND & $62,70,71$ \\
\hline MuSK, muscle-specific kinase receptor & AEGTVSV & $\mathrm{Y} 2 \mathrm{H}$ & ND & ND & 8 \\
\hline Nectin $1 \alpha$, herpesvirus Ig-like receptor & SKKEWYV & $\mathrm{Y} 2 \mathrm{H}$, in vitro & Yes & ND & 67 \\
\hline Nectin $2 \alpha$, herpesvirus Ig-like receptor & SRRAVYV & $\mathrm{Y} 2 \mathrm{H}$ & ND & ND & 67 \\
\hline Nectin $2 \delta$, herpesvirus Ig-like receptor & MSRAMYV & $\mathrm{Y} 2 \mathrm{H}$ & ND & ND & 67 \\
\hline Nectin $3 \alpha$, herpesvirus Ig-like receptor & SRREWYV & $\mathrm{Y} 2 \mathrm{H}$ & ND & ND & 67 \\
\hline NET, norepinephrine transporter & LQHWLAI & $\mathrm{Y} 2 \mathrm{H}$ & ND & ND & 6 \\
\hline PrRP-R, prolactin-releasing peptide receptor & MTVSVVI & In vitro & Yes & ND & 72 \\
\hline Serine racemase & SYQSVSV & $\mathrm{Y} 2 \mathrm{H}$, in vitro & No & $\mathrm{N} / \mathrm{A}$ & 54 \\
\hline $\mathrm{UNC} 5 \mathrm{H} 1$, netrin receptor & TVSEAEC & $\mathrm{Y} 2 \mathrm{H}$, in vitro, in vivo & Yes & Yes & 33 \\
\hline \multicolumn{6}{|l|}{ Others } \\
\hline Aquaporin 1, water channel & RVEMKPK & $\mathrm{Y} 2 \mathrm{H}$, in vitro & ND & ND & 58 \\
\hline Arf1, ADP-ribosylation factor & NQLRNQK & $\mathrm{Y} 2 \mathrm{H}$ & ND & $\mathrm{N} / \mathrm{A}$ & 27 \\
\hline Arf3, ADP-ribosylation factor & NQLKNKK & $\mathrm{Y} 2 \mathrm{H}$ & ND & $\mathrm{N} / \mathrm{A}$ & 27 \\
\hline mGluR4a, metabotropic glutamate receptor & TYTNHAI & $\mathrm{Y} 2 \mathrm{H}$ & ND & ND & 62 \\
\hline mGluR8a, metabotropic glutamate receptor & SYSDHSI & $\mathrm{Y} 2 \mathrm{H}$ & ND & ND & 62 \\
\hline Nectin $3 \beta$, herpesvirus Ig-like receptor & NPREHYV & $\mathrm{Y} 2 \mathrm{H}$ & ND & ND & 67 \\
\hline Nectin 4, herpesvirus Ig-like receptor & NGRGHLV & $\mathrm{Y} 2 \mathrm{H}$ & ND & ND & 67 \\
\hline TIS21, NGF-inducible protein & YVMAVSS ${ }^{a}$ & $\mathrm{Y} 2 \mathrm{H}$, in vitro & ND & $\mathrm{N} / \mathrm{A}$ & 73 \\
\hline SER, serotonin transporter & DIRLNAV & $\mathrm{Y} 2 \mathrm{H}$ & ND & ND & 6 \\
\hline
\end{tabular}

Proteins in italic are non-membrane proteins. $\mathrm{Y} 2 \mathrm{H}=$ Yeast two-hybrid; $\mathrm{ND}=$ not done; $\mathrm{N} / \mathrm{A}=$ not applicable. In vitro interaction characterization includes co-immunoprecipitation from overexpression in heterologous cells, GST pulldown and immuno-fluorescent experiments. In vivo interaction indicates detection of interaction from native tissues such as brain homogenate.

a The exact interaction sequence has not been determined, the C-terminal sequence of TIS21 is shown. 
ranging from protein phosphorylation, neurotransmission to cell adhesion. In the cases where the interaction sites were determined, it is usually the C-termini of these proteins that interact with PICK1. According to their Ctermini, these proteins were classified to three categories: type I, type II PDZ-binding motif, and others (table 1). While PICK1's PDZ domain binds to both type I and type II PDZ-binding motifs, the majority of the PICK1's PDZ ligands can be classified as type II. Furthermore, while the interactions of PICK1 to several type II PDZ-binding motifs have been confirmed in vivo, no type I motif has been done so (table 1). This suggests that the PDZ domain of PICK1 does have a preference for type II motif. Indeed, it was found that the affinity of PICK1's PDZ domain to type II motif is much higher than to type I $[19,20]$.

\section{BAR Domain of PICK1 Binds to Lipid}

The BAR domain is a protein module of about 200 amino acid residues. It was frequently found in proteins involved in membrane trafficking, especially endocytosis. The prototypical BAR domain-containing protein amphiphysin plays important roles in endocytosis of synaptic vesicles [21,22]. The BAR domain of amphiphysin could directly bind to liposomes, with binding affinity varying according to the diameters of liposomes. In addition, the BAR domain can deform liposomes to form tubules [23,24]. This suggests that the BAR domain could serve as a membrane curvature sensor or actively bends the membrane to induce formation of trafficking vesicles.

A crystallographic study of the Drosophila amphiphy$\sin$ BAR domain revealed that a complete BAR domain is a crescent-shaped dimer [24] (fig. 3). In other words, a BAR domain module in a protein is actually half of a BAR domain. It has to join with another BAR domain from the same protein (homodimer) or a different protein (heterodimer) to form a fully functional BAR domain. The full BAR domain is made of six helical bundles, with each monomer contributing three helices. There are four positively charged groups that are important for BAR domain's function. Two locate at both ends of the crescent dimer and two locate at the concave surface of the dimer (fig. 3). These positively charged residues are responsible for binding to negatively charged lipid molecules such as phosphoinositides. This provides the structure basis for BAR domain's lipid binding [24].

The central region of PICKl's was initially predicted to form coiled-coil repeats. These repeats have high se- quence homology to proteins called arfaptins. Arfaptins, which include arfaptin 1 and arfaptin 2, are a group of proteins that bind to small $\mathrm{G}$ proteins such as Arf and Rac [25]. The sequence of PICK1 and arfaptin is not very similar to the prototypical amphiphysin BAR domains. As such, they were not recognized as BAR domains initially. However, when the crystal structure of the BAR domain was resolved [24], it was found to have a similar structure to the GTPase-binding domain of arfaptin 2 [25]. It was subsequently confirmed that similar to the amphiphysin BAR domain, the GTPase-binding domain of arfaptin 2 could also bind and tubulate liposomes [24]. Mutating the positively charged residues of arfaptin 2 also eliminates its lipid-binding capability. These results indicate that the GTPase domain of arfaptin 2 is a bona fida lipidbinding BAR domain.

The sequence homology of PICK1 with arfaptin 2 suggests that the coiled-coil repeats in the central region of PICK1 may also be a lipid-binding BAR domain. Sequence alignment of PICK1, arfaptin 2 and amphiphysin indicates that the positive charged residues responsible for lipid binding are conserved in PICK1's BAR domain (fig. 3). Using liposome sedimentation assay and lipid strip overlay assay, we recently demonstrated that the BAR domain of PICK1 indeed binds to lipid molecules [26]. The lipid molecules that interact with PICK1 are mainly negatively charged phosphoinositides. Similar to other BAR domains, PICK1's lipid binding is mainly mediated by two groups of positively charged residues. Lysine 266 and $268(\mathrm{~K} 266,268)$ are predicted to locate at the end of the crescent-shaped dimer and lysine 251, 252 and $257(\mathrm{~K} 251,252,257)$ are predicted to locate at the concave surface of the dimer. Mutations of either group significantly reduced PICK1's lipid-binding capability [26]. Furthermore, lipid binding of PICK1's BAR domain was found to be both positively and negatively regulated by other regions of PICK1. The PDZ domain and the linker region of PICK1 enhance BAR domain's lipid binding and the C-terminal region of PICK1 inhibits its lipid binding.

The BAR domain of PICK1 is most close to arfaptins. The BAR domains of arfaptins were shown to directly bind to small GTPase such as Arf1 and Rac1 [25]. This raises the question of whether PICK1's BAR domain could also bind to a small GTPase. This idea was explored using a yeast two-hybrid technique. While Arf1 and Arf3 were found to interact with PICK1, they do not bind to the BAR domain of PICK1 [27]. Instead, they were found to interact with the PDZ domain of PICK1. The interaction of Arfs with PICK1 has yet to be confirmed in vivo 
and the physiological function of this interaction is not clear. It remains an open question whether and what GTPase binds to the BAR domain of PICK1.

Apart from interaction with lipid molecules and selfassociation, the BAR domain of PICK1 has being reported to interact with several other proteins. Using fusion protein in vitro binding assay, deleting the BAR domain of PICK1 was found to disrupt its interaction with GluR2 [28]. A region located 30-40 residues upstream of GluR2 C-terminus is believed to be important for this interaction. Using a similar in vitro binding assay, PICK1 was found to interact with both $\alpha$-SNAP and $\beta$-SNAP (soluble NSF attachment protein), two proteins required for disassembly of SNARE complexes during membrane fusion [28]. NSF was found to disassemble the PICK1GluR2 complex in the presence of $\alpha$-SNAP. Intriguingly, GRIP (glutamate receptor interacting protein), another PDZ domain containing protein that interacts with GluR2 [29], was also found to interact with the BAR domain of PICK1 and this interaction is involved in AMPA receptor trafficking [30]. More recently, the membrane proximal region of GluR $\delta 2$ was reported to interact with part of PICK1's BAR domain (aa 245-278) and this interaction is important for synaptic plasticity at cerebellar Purkinje neurons [31].

\section{The N-Terminal Acidic Region, Linker Region and C-Terminal Acidic Region of PICK1}

In addition to the PDZ and BAR domains, there are three short regions in PICK1. A short region with about 18 amino acid residues locates at the extreme $\mathrm{N}$-terminus of PICK1. This short region is enriched with acidic amino acid residues. The N-terminal acidic region (NAR) of PICK1 was reported to directly bind to $\mathrm{Ca}^{2+}[32]$. The binding of $\mathrm{Ca}^{2+}$ regulates the affinity of PICK1's interaction to GluR2. The optimal $\mathrm{Ca}^{2+}$ concentration for PICK1 and GluR2 interaction was determined to be around 15 $\mu \mathrm{M}$. Deletion of the $\mathrm{N}$-terminal region renders the interaction of PICK1 and GluR2 insensitive to $\mathrm{Ca}^{2+}$. The $\mathrm{Ca}^{2+}$ binding of PICK1 was also found to be important to AMPA receptor trafficking regulated by activation of NMDA receptors.

Between the PDZ domain and BAR domain of PICK1, a linker region of about 40 amino acids is predicted to form a helical structure. It has been reported that in some BAR domains, a short sequence before the BAR domain could form an amphipathic helix. The helix could enhance BAR domain's lipid-binding capabilities by inserting themselves into lipids [24]. This kind of BAR domain is called N-BAR. The linker region of PICK1 was predicted to form a helical structure and it is likely that the BAR domain of PICK1 is one of the NBAR. Indeed, the linker region was found to enhance lipid binding of PICK1's BAR domain [26]. In addition to the linker region, the PDZ domain of PICK1 was also found to enhance its lipid binding. It is not clear at this moment how the PDZ domain enhances PICKl's lipid binding.

The C-terminal region of PICK1 contains a stretch of acidic residues that are highly conserved across species (4 in C. elegans, 9 in humans and 17 in sea urchins) (fig. 1). The C-terminal acid region (CAR) of PICK1 was found to inhibit lipid binding of PICK1's BAR domain [26]. Without the presence of the PDZ domain and the linker region, the C-terminal region of PICK1 could completely abolish PICK1 BAR domain's lipid-binding capability [26]. This autoinhibition is likely due to the negatively charged acidic residues of PICK1's C-terminal region fold back and bind to the positively charged residue of PICKl's BAR domain to inhibit its lipid binding. It has been reported that the C-terminal acidic region also has weak $\mathrm{Ca}^{2+}$-binding affinity [32]. It would be interesting to examine if the autoinhibition of lipid binding could be regulated by $\mathrm{Ca}^{2+}$ or other mechanisms, which will make PICK1's lipid binding more dynamic. In fact, deletion of the C-terminal region has been reported to increase synaptic targeting of PICK1 in neurons [19], suggesting that the autoinhibitory effect of PICKl's C-terminal region may have physiological significance.

\section{PICK1 Functions as a Protein-Trafficking Regulator}

PICK1 binds to a large number of proteins, especially membrane proteins. In most of the cases, the binding of PICK1 regulates the trafficking of its binding partners by altering either their subcellular targeting and/or surface expression (table 1). For example, PICK1 induces clustering of ephrein-B1 and Eph receptor EphB2 when co-expressed in heterologous cells [7]. PICK1 was also found to alter the surface expression of netrin receptor UNC5H1 and regulate netrin-mediated axon outgrowth [33, 34]. Here we use the extensively studied interaction of PICK1 and AMPA receptors as an example to illustrate how PICK1 regulates trafficking and function of membrane proteins.

PICK1 was found to interact with AMPA receptor subunits GluR2, 3 and 4c in yeast two-hybrid assays $[4,35]$. 
Fig. 3. The BAR domain of PICK1. a Ribbon diagram of a human arfaptin-2 structure. The line with blue waves represents lipid bilayer membrane. Red balls represent positively charged residues responsible for lipid binding. Blue balls represent negatively charged phospholipids that interact with positively charged residues of the BAR domain. The diagram was generated by Molmol using the structure file (1I49) from the PDB database. b Sequence alignment of BAR domains from rat PICK1 (NP_445912), human arfaptin 2 (NP_ 036534) and rat amphiphysin 1 (NP_ 071553). Highlighted residues are positively charged amino acid residues that are responsible for lipid binding.

Fig. 4. A model of PICK1-regulated AMPA receptor trafficking. A model illustrates that by binding to negatively charged lipids, PICK1 maintains an intracellular reserve pool of AMPA receptors and regulates trafficking of AMPA receptors between the intracellular reserve pool and surface by facilitating formation of trafficking vesicles. Red colored dots on the membrane represent a negatively charged lipid.

Structure and Function of PICK1

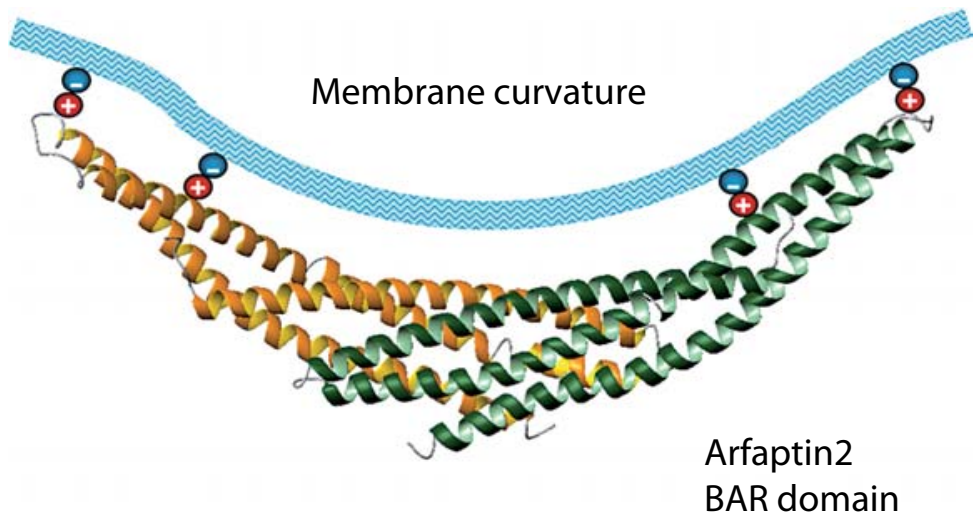

b

rPICK1

hArfaptin2

rAmphiphysin1

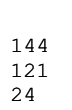

Helix 1

---ICNDGLVKRTEELERTAELYKGMTEHTKNLTRAFYELSOTHRAFGDVFSVTGVREPO ---TVDT VIOKTGKADETKDEOFEEYVONGROOEAEGTRTORETRGYTAATKGMOEASMKTTESTIE

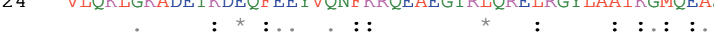

rPICK1

hArfaptin2

rAmphiphysin1

201 Helix 2 $169---A D E F G Y N A E T O K L L C K N G E T L I G A V N F F V S S I N T L V T K T M E D T L M T V K O Y E A A R--$ 84 VYEPDWYGR-- FDVIKMYGEKCDUTT

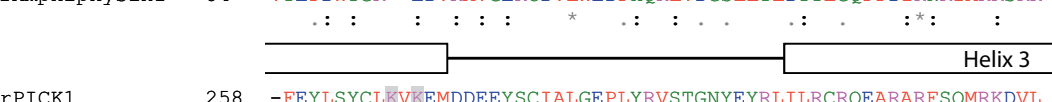

IPICK1 258 -FEYLSYCLKVKEMDDEEYSCIALGEPLYRVSTGNYEYRLILRCRQEARARFSQMRKDVL rAmphiphysin1 223 -LEYDAYRTDLEELS-------SKRKDESRTSKAEEEFOKAOKVFEEFNVDIOEFT PSTWT

** $:$ * : $\quad *$ :

IPICK1 317 EKMELIDQKHVQDIVFQLQRFVSTMSKYYNDCYAVLRDADV----

hArfaptin2 281 IKLKFLEENKIKVMHKQLLLFHNAVSAYFAGNQKQLEQTLQ----

rAmphiphysin1 196 SRRVGFYVNTFKNVSSLEAKFHKEIAVLCHKLYEVMTKLGDQHAD

: : : : : : * : :

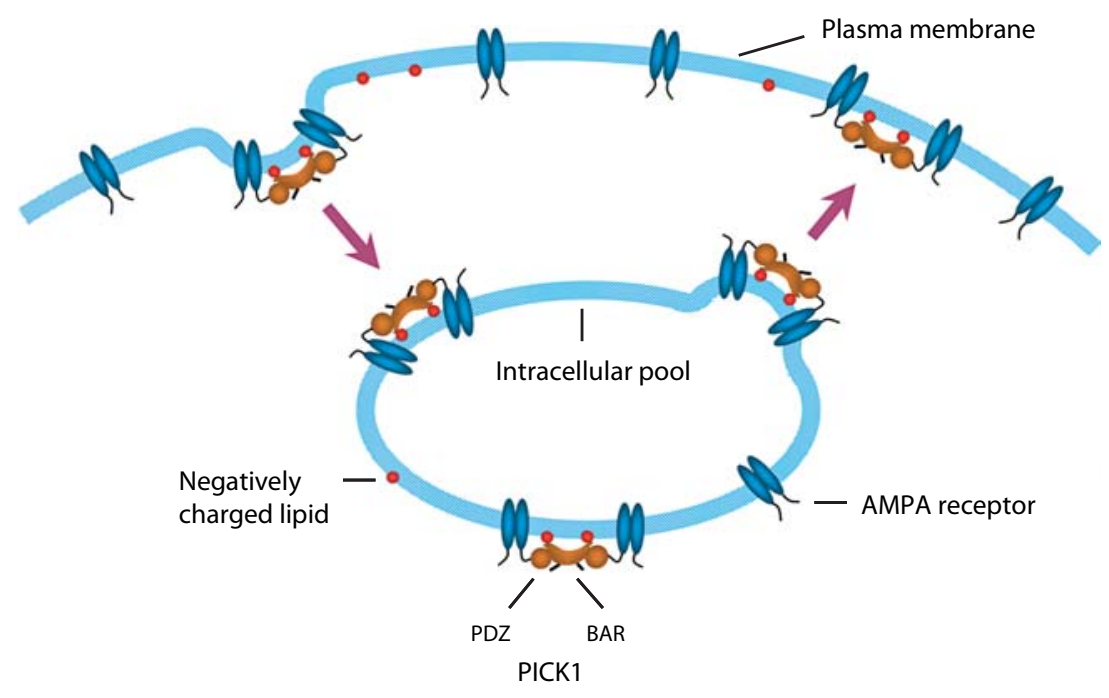


The interaction of PICK1 with GluR2 was subsequently verified by co-immunoprecipitation (co-IP) from heterologous cells and in vivo co-IP from rat brain homogenate. When co-expressed in heterologous cells, PICK1 forms many co-clusters with GluR2 in the cytosol. The nature of these clusters is unclear at this moment but they are unlikely to be just simple aggregation of proteins, as the formation of these clusters requires PICKl's lipidbinding capability [26]. The clustering of GluR2 requires the interaction of PICK1 and GluR2, as either mutation at the PDZ domain of PICK1 (K27D28 to AA) or deletion at the C-terminus of GluR2 disrupt the co-clusters [4]. In neurons, PICK1 was found to co-localize with GluR2 in synapses. PICK1 has the ability to bring AMPA receptors to synapses as overexpression of wild-type PICK1 increases the synaptic GluR1 and GluR2 [26]. This is also dependent on the interaction between PICK1 and GluR2, as PDZ mutant of PICK1 failed to target AMPA receptors to synapses. In addition to regulating the subcellular localization of AMPA receptors, PICK1 also alters the surface expression of GluR2. Overexpression of PICK1 reduced surface expression of GluR2, as measured by surface biotinylation assay and immunostaining of surface receptors $[5,26,36]$.

More interestingly, PICK1 was found to regulate the dynamic trafficking of AMPA receptor during synaptic plasticity. Forms of synaptic plasticity such as long-term potentiation (LTP, where synaptic response is increased) and long-term depression (LTD, where synaptic response is decreased) are regarded as the cellular basis of learning and memory [37]. A great deal of evidence suggests that LTP and LTD could be the result of an increasing or decreasing number of AMPA receptors at the synaptic surface, respectively [38]. Disrupting the interaction between PICK1 and GluR2 using the last 20 amino acids of GluR2 or an antibody targeting the PDZ domain of PICK1 inhibited expression of LTD in cerebellar Purkinje neurons $[39,40]$ and hippocampal pyramidal neurons [41]. A PDZ mutant of PICK1 was also found to inhibit LTD in Purkinje neurons, indicating the requirement of PICK1-GluR2 interaction for LTD [40]. This is further confirmed in PICK1 knockout mice, where LTD was found to be completely abolished in cerebellar Purkinje neurons [3]. Transfecting wild-type PICK1 rescued the LTD but the PDZ mutant of PICK1 failed to do so. These results provided strong evidence to support the role of PICK1 in the removal of AMPA receptors from the synaptic surface during LTD in cerebellar Purkinje neurons.
Protein phosphorylation was found to play important roles in PICK1-mediated AMPA receptor trafficking and synaptic plasticity. The serine 880 of GluR2, which locates at the -3 position of GluR2 C-terminus, could be phosphorylated by protein kinase C $[42,43]$. The phosphorylation of S 880 does not change PICK1's interaction with GluR2 but significantly reduces binding of GluR2 to GRIP. By disrupting the interaction with GRIP, phosphorylation of S880 by PKC was found to promote interaction of GluR2 with PICK1 and facilitate PICK1-mediated internalization of AMPA receptors during LTD [5, 39, 43-45].

PICK1's lipid-binding capability was found to be important for its function in AMPA receptor trafficking as well. The lipid-binding deficient BAR domain mutant PICK1 2K-E (K266,268 mutated to E) could no longer cluster GluR2 when co-expressed in the heterologous system [26]. The BAR domain mutant of PICK1 also lost its ability to regulate surface expression of GluR2. Furthermore, the BAR domain mutant of PICK1 lost its ability to target to synapses in neurons. Consequently, the BAR domain mutant of PICK1 could not bring AMPA receptors to synapses [26]. In an electrophysiological study, the BAR domain mutant of PICK1 was found to inhibit expression of LTD [26]. The role of PICK1's BAR domain in LTD was further verified in PICK1 knockout mice. While expression of wild-type PICK1 could rescue PICK1 knockout mice's deficiency in cerebellar LTD, the BAR domain mutant PICK1 was not able to do so [3]. Taken together, this suggests a mechanism for PICK1mediated AMPA receptor trafficking: while PICK1's PDZ domain binds to the C-termini of AMPA receptors, its BAR domain binds to negatively charged lipids and tethers the AMPA receptors as cargo to curved-membrane microdomains that are designated to form trafficking vesicles (fig. 4). As PICK1 interacts with a number of other membrane proteins, it could be a general mechanism for PICK1 to regulate the trafficking of membrane proteins via the lipid-binding capability of its BAR domain.

While most studies suggest that PICK1 is involved in endocytosis of AMPA receptors, evidence has started to emerge that PICK1 could also be involved in the insertion of AMPA receptors to cell surface. In the cerebellar stellate cells, repetitive stimulation of parallel fiber could induce insertion of GluR2-containing receptors to the surface of synapses [46]. The interaction of PICK1 with GluR2 was found to be important in this process, as blocking the interaction between GluR2 and PICK1 inhibits the insertion of GluR2 to surface $[2,47]$. Furthermore, the delivery of GluR2 to surface was also impaired 
in PICK1 knockout mice [2]. These results support a role of PICK1 in insertion or exocytosis of AMPA receptors. To reconcile the role of PICK1 in both endocytosis and exocytosis, we propose that PICK1 may maintain an intracellular pool of AMPA receptors at synapses and serve as a shuttle between the intracellular and surface pool of AMPA receptors (fig. 4).

Most current studies of PICK1 focus on its cellular function, especially its roles in membrane protein trafficking. The function of PICK1 in whole organisms has not been adequately addressed. While PICK1 knockout mice were found to have a deficiency in trafficking of AMPA receptor and synaptic plasticity $[2,3]$, it remains to be tested if these cellular deficiencies would manifest in animal behavior such as learning and memory. It is interesting to note that PICK1 has been implicated in mental disorders. In humans, PICK1 is localized at chromosome 22q13.1. This region was found to have a significant association with schizophrenia and bipolar disorder [48-53]. Using an association study, polymorphisms of PICK1 were found to correlate with schizophrenia [54, 55]. It was also reported that schizophrenia patients had a decreased PICK1 mRNA level in the cortex by in situ hybridization [56], but in a separate report, no significant change on PICK1's mRNA level was detected by real-time PCR from the cortex of elderly schizophrenia patients [57]. It is not clear what role PICK1 may play in schizophrenia, but PICKl's interaction with monoamine transporters, serine racemase, glutamate receptors and other neuronal proteins could contribute to the disorder. Further investigations are needed to clarify the role of PICK1 in schizophrenia and other mental disorders.

\section{Acknowledgements}

This work was supported in part by grants from the Research Grants Council of the Hong Kong Special Administrative Region, China (HKUST6144/03M, HKUST6130/04M and N_HKUST $621 / 04)$.

\section{References}

1 Staudinger J, Zhou J, Burgess R, Elledge SJ, Olson EN: PICK1: a perinuclear binding protein and substrate for protein kinase $\mathrm{C}$ isolated by the yeast two-hybrid system. J Cell Biol 1995;128:263-271.

$\checkmark 2$ Gardner SM, Takamiya K, Xia J, et al: Calcium-permeable AMPA receptor plasticity is mediated by subunit-specific interactions with PICK1 and NSF. Neuron 2005;45:903915.

3 Steinberg JP, Takamiya K, Shen Y, et al: Targeted in vivo mutations of the AMPA receptor subunit GluR2 and its interacting protein PICK1 eliminate cerebellar long-term depression. Neuron 2006;49:845-860.

-4 Xia J, Zhang X, Staudinger J, Huganir RL: Clustering of AMPA receptors by the synaptic PDZ domain-containing protein PICK1. Neuron 1999;22:179-187.

5 Perez JL, Khatri L, Chang C, Srivastava S, Osten P, Ziff EB: PICK1 targets activated protein kinase $\mathrm{C} \alpha$ to AMPA receptor clusters in spines of hippocampal neurons and reduces surface levels of the AMPA-type glutamate receptor subunit 2. J Neurosci 2001; 21:5417-5428.

-6 Torres GE, Yao WD, Mohn AR, et al: Functional interaction between monoamine plasma membrane transporters and the synaptic PDZ domain-containing protein PICK1. Neuron 2001;30:121-134.
Torres R, Firestein BL, Dong H, et al: PDZ proteins bind, cluster, and synaptically colocalize with Eph receptors and their ephrin ligands. Neuron 1998;21:1453-1463.

$\checkmark 8$ Jaulin-Bastard F, Saito H, Le Bivic A, et al: The ERBB2/HER2 receptor differentially interacts with ERBIN and PICK1 PSD-95/ DLG/ZO-1 domain proteins. J Biol Chem 2001;276:15256-15263.

-9 McInvale AC, Staudinger J, Harlan RE, Garcia MM: Immunolocalization of PICK1 in the ascending auditory pathways of the adult rat. J Comp Neurol 2002;450:382-394.

$>10$ Wang WL, Yeh SF, Chang YI, et al: PICK1, an anchoring protein that specifically targets protein kinase $\mathrm{C} \alpha$ to mitochondria selectively upon serum stimulation in NIH 3T3 cells. J Biol Chem 2003;278:37705-37712.

11 Sheng M, Sala C: PDZ domains and the organization of supramolecular complexes. Annu Rev Neurosci 2001;24:1-29.

12 Brenman JE, Chao DS, Gee SH, et al: Interaction of nitric oxide synthase with the postsynaptic density protein PSD-95 and $\alpha_{1}$-syntrophin mediated by PDZ domains. Cell 1996;84:757-767.

13 Zimmermann P, Meerschaert K, Reekmans $\mathrm{G}$, et al: $\mathrm{PIP}_{2}$-PDZ domain binding controls the association of syntenin with the plasma membrane. Mol Cell 2002;9:1215-1225.

-14 Stricker NL, Christopherson KS, Yi BA, et al: PDZ domain of neuronal nitric oxide synthase recognizes novel C-terminal peptide sequences. Nat Biotechnol 1997;15:336-342.
15 Tochio H, Zhang Q, Mandal P, Li M, Zhang $\mathrm{M}$ : Solution structure of the extended neuronal nitric oxide synthase PDZ domain complexed with an associated peptide. Nat Struct Biol 1999;6:417-421.

16 Sheng M: Molecular organization of the postsynaptic specialization. Proc Natl Acad Sci USA 2001;98:7058-7061.

17 Tsunoda S, Sierralta J, Sun Y, et al: A multivalent PDZ-domain protein assembles signalling complexes in a G-protein-coupled cascade. Nature 1997;388:243-249.

-18 Staudinger J, Lu J, Olson EN: Specific interaction of the PDZ domain protein PICK1 with the $\mathrm{COOH}$ terminus of protein kinase C- $\alpha$. J Biol Chem 1997;272:32019-32024.

19 Boudin H, Craig AM: Molecular determinants for PICK1 synaptic aggregation and mGluR7a receptor coclustering: role of the PDZ, coiled-coil, and acidic domains. J Biol Chem 2001;276:30270-30276.

20 Madsen KL, Beuming T, Niv MY, et al: Molecular determinants for the complex binding specificity of the PDZ domain in PICK1. J Biol Chem 2005;280:20539-20548.

21 Wigge P, McMahon HT: The amphiphysin family of proteins and their role in endocytosis at the synapse. Trends Neurosci 1998; 21:339-344.

22 Slepnev VI, De Camilli P: Accessory factors in clathrin-dependent synaptic vesicle endocytosis. Nat Rev Neurosci 2000;1:161-172. 
23 Takei K, Slepnev VI, Haucke V, De Camilli P: Functional partnership between amphiphysin and dynamin in clathrin-mediated endocytosis. Nat Cell Biol 1999;1:33-39.

24 Peter BJ, Kent HM, Mills IG, et al: BAR domains as sensors of membrane curvature: the amphiphysin BAR structure. Science 2004;303:495-499.

25 Tarricone C, Xiao B, Justin N, et al: The structural basis of arfaptin-mediated crosstalk between Rac and Arf signalling pathways. Nature 2001;411:215-219.

26 Jin W, Ge WP, Xu J, et al: Lipid binding regulates synaptic targeting of PICK1, AMPA receptor trafficking, and synaptic plasticity. J Neurosci 2006;26:2380-2390.

-27 Takeya R, Takeshige K, Sumimoto H: Interaction of the PDZ domain of human PICK1 with class I ADP- ribosylation factors. Biochem Biophys Res Commun 2000;267:149155.

28 Hanley JG, Khatri L, Hanson PI, Ziff EB: NSF ATPase and $\alpha-/ \beta$-SNAPs disassemble the AMPA receptor-PICK1 complex. Neuron 2002;34:53-67.

-29 Dong H, Zhang P, Song I, Petralia RS, Liao D, Huganir RL: Characterization of the glutamate receptor-interacting proteins GRIP1 and GRIP2. J Neurosci 1999;19:6930-6941.

- $30 \mathrm{Lu}$ W, Ziff EB: PICK1 interacts with ABP/ GRIP to regulate AMPA receptor trafficking. Neuron 2005;47:407-421.

- 31 Yawata S, Tsuchida H, Kengaku M, Hirano T: Membrane-proximal region of glutamate receptor $\delta 2$ subunit is critical for long-term depression and interaction with protein interacting with $C$ kinase 1 in a cerebellar Purkinje neuron. J Neurosci 2006;26:36263633.

-32 Hanley JG, Henley JM: PICK1 is a calciumsensor for NMDA-induced AMPA receptor trafficking. EMBO J 2005;24:3266-3278.

- 33 Williams ME, Wu SC, McKenna WL, Hinck L: Surface expression of the netrin receptor $\mathrm{UNC} 5 \mathrm{H} 1$ is regulated through a protein kinase $\mathrm{C}$-interacting protein/protein kinasedependent mechanism. J Neurosci 2003;23: 11279-11288.

34 Bartoe JL, McKenna WL, Quan TK, et al: Protein interacting with C-kinase 1/protein kinase $\mathrm{C} \alpha$-mediated endocytosis converts netrin-1-mediated repulsion to attraction. J Neurosci 2006;26:3192-3205.

- 35 Dev KK, Nishimune A, Henley JM, Nakanishi S: The protein kinase C- $\alpha$ binding protein PICK1 interacts with short but not long form alternative splice variants of AMPA receptor subunits. Neuropharmacology 1999; 38:635-644.

-36 Terashima A, Cotton L, Dev KK, et al: Regulation of synaptic strength and AMPA receptor subunit composition by PICK1. J Neurosci 2004;24:5381-5390.

- 37 Bliss TV, Collingridge GL: A synaptic model of memory: long-term potentiation in the hippocampus. Nature 1993;361:31-39.
38 Malinow R, Malenka RC: AMPA receptor trafficking and synaptic plasticity. Annu Rev Neurosci 2002;25:103-126.

39 Matsuda S, Launey T, Mikawa S, Hirai H: Disruption of AMPA receptor GluR2 clusters following long-term depression induction in cerebellar Purkinje neurons. EMBO J 2000;19:2765-2774

40 Xia J, Chung HJ, Wihler C, Huganir RL, Linden DJ: Cerebellar long-term depression requires PKC-regulated interactions between GluR2/3 and PDZ domain-containing proteins. Neuron 2000;28:499-510.

41 Kim CH, Chung HJ, Lee HK, Huganir RL: Interaction of the AMPA receptor subunit GluR2/3 with PDZ domains regulates hippocampal long-term depression. Proc Natl Acad Sci USA 2001;98:11725-11730.

42 Matsuda S, Mikawa S, Hirai H: Phosphorylation of serine- 880 in GluR 2 by protein kinase $\mathrm{C}$ prevents its $\mathrm{C}$ terminus from binding with glutamate receptor-interacting protein. J Neurochem 1999;73:1765-1768.

43 Chung HJ, Xia J, Scannevin RH, Zhang X, Huganir RL: Phosphorylation of the AMPA receptor subunit GluR2 differentially regulates its interaction with PDZ domain-containing proteins. J Neurosci 2000;20:72587267.

44 Chung HJ, Steinberg JP, Huganir RL, Linden DJ: Requirement of AMPA receptor GluR2 phosphorylation for cerebellar long-term depression. Science 2003;300:1751-1755.

45 Seidenman KJ, Steinberg JP, Huganir R, Malinow R: Glutamate receptor subunit 2 serine 880 phosphorylation modulates synaptic transmission and mediates plasticity in CA1 pyramidal cells. J Neurosci 2003;23:92209228.

46 Liu SQ, Cull-Candy SG: Synaptic activity at calcium-permeable AMPA receptors induces a switch in receptor subtype. Nature 2000; 405:454-858.

47 Liu SJ, Cull-Candy SG: Subunit interaction with PICK and GRIP controls $\mathrm{Ca}^{2+}$ permeability of AMPARs at cerebellar synapses. Nat Neurosci 2005;8:768-775.

-48 Pulver AE, Karayiorgou M, Lasseter VK, et al: Follow-up of a report of a potential linkage for schizophrenia on chromosome 22q12-q13.1. Part 2. Am J Med Genet 1994; 54:44-50.

-49 Pulver AE, Karayiorgou M, Wolyniec PS, et al: Sequential strategy to identify a susceptibility gene for schizophrenia: report of potential linkage on chromosome 22q12-q13.1. Part 1. Am J Med Genet 1994;54:36-43.

50 Coon H, Holik J, Hoff M, et al: Analysis of chromosome 22 markers in nine schizophrenia pedigrees. Am J Med Genet 1994;54:7279 .

51 Schwab SG, Lerer B, Albus M, et al: Potential linkage for schizophrenia on chromosome 22q12-q13: a replication study. Am J Med Genet 1995;60:436-443.
52 DeLisi LE, Shaw SH, Crow TJ, et al: A genome-wide scan for linkage to chromosomal regions in 382 sibling pairs with schizophrenia or schizoaffective disorder. Am J Psychiatry 2002;159:803-812.

53 Berrettini WH: Susceptibility loci for bipolar disorder: overlap with inherited vulnerability to schizophrenia. Biol Psychiatry 2000; 47:245-251.

54 Fujii K, Maeda K, Hikida T, et al: Serine racemase binds to PICK1: potential relevance to schizophrenia. Mol Psychiatry 2006;11: 150-147.

55 Hong CJ, Liao DL, Shih HL, Tsai SJ: Association study of PICK1 rs3952 polymorphism and schizophrenia. Neuroreport 2004;15: 1965-1967.

56 Beneyto M, Meador-Woodruff JH: Laminaspecific abnormalities of AMPA receptor trafficking and signaling molecule transcripts in the prefrontal cortex in schizophrenia. Synapse 2006;60:585-598.

-57 Dracheva S, McGurk SR, Haroutunian V: mRNA expression of AMPA receptors and AMPA receptor binding proteins in the cerebral cortex of elderly schizophrenics. J Neurosci Res 2005;79:868-878.

58 Cowan CA, Yokoyama N, Bianchi LM, Henkemeyer M, Fritzsch B: EphB2 guides axons at the midline and is necessary for normal vestibular function. Neuron 2000;26:417430.

59 Excoffon KJ, Hruska-Hageman A, Klotz M, Traver GL, Zabner J: A role for the PDZbinding domain of the coxsackie $B$ virus and adenovirus receptor (CAR) in cell adhesion and growth. J Cell Sci 2004;117:4401-4409.

60 Hirbec H, Francis JC, Lauri SE, et al: Rapid and differential regulation of AMPA and kainate receptors at hippocampal mossy fibre synapses by PICK1 and GRIP. Neuron 2003;37:625-638.

61 Penzes P, Johnson RC, Sattler R, et al: The neuronal Rho-GEF kalirin-7 interacts with $\mathrm{PDZ}$ domain-containing proteins and regulates dendritic morphogenesis. Neuron 2001; 29:229-242.

62 El Far O, Airas J, Wischmeyer E, Nehring $\mathrm{RB}$, Karschin A, Betz H: Interaction of the C-terminal tail region of the metabotropic glutamate receptor 7 with the protein kinase C substrate PICK1. Eur J Neurosci 2000;12: 4215-4221.

63 Meyer G, Varoqueaux F, Neeb A, Oschlies M, Brose N: The complexity of PDZ domainmediated interactions at glutamatergic synapses: a case study on neuroligin. Neuropharmacology 2004;47:724-733

64 Hruska-Hageman AM, Wemmie JA, Price MP, Welsh MJ: Interaction of the synaptic protein PICK1 (protein interacting with $\mathrm{C}$ kinase 1) with the non-voltage gated sodium channels BNCl (brain $\mathrm{Na}^{+}$channel 1) and ASIC (acid-sensing ion channel). Biochem J 2002;361:443-450. 
-65 Duggan A, Garcia-Anoveros J, Corey DP: The PDZ domain protein PICK1 and the sodium channel $\mathrm{BNaC} 1$ interact and localize at mechanosensory terminals of dorsal root ganglion neurons and dendrites of central neurons. J Biol Chem 2002;277:5203-5208.

-66 Leonard AS, Yermolaieva O, Hruska-Hageman A, et al: cAMP-dependent protein kinase phosphorylation of the acid-sensing ion channel-1 regulates its binding to the protein interacting with C-kinase-1. Proc Natl Acad Sci USA 2003;100:2029-2034.

-67 Reymond N, Garrido-Urbani S, Borg JP, Dubreuil P, Lopez M: PICK-1: a scaffold protein that interacts with nectins and JAMs at cell junctions. FEBS Lett 2005;579:2243-2249.
68 Boudin H, Doan A, Xia J, et al: Presynaptic clustering of mGluR7a requires the PICK1 PDZ domain binding site. Neuron 2000;28: 485-497.

69 Dev KK, Nakajima Y, Kitano J, Braithwaite SP, Henley JM, Nakanishi S: PICK1 interacts with and regulates PKC phosphorylation of mGLUR7. J Neurosci 2000;20:7252-7257.

70 Enz R, Croci C: Different binding motifs in metabotropic glutamate receptor type $7 \mathrm{~b}$ for filamin $\mathrm{A}$, protein phosphatase $1 \mathrm{C}$, protein interacting with protein kinase $\mathrm{C}$ (PICK) 1 and syntenin allow the formation of multimeric protein complexes. Biochem J 2003; 372:183-191.
71 Perroy J, El Far O, Bertaso F, et al: PICK1 is required for the control of synaptic transmission by the metabotropic glutamate receptor 7. EMBO J 2002;21:2990-2999.

72 Lin SH, Arai AC, Wang Z, Nothacker HP, Civelli O: The carboxyl terminus of the prolactin-releasing peptide receptor interacts with PDZ domain proteins involved in $\alpha$ amino-3-hydroxy-5-methylisoxazole-4propionic acid receptor clustering. Mol Pharmacol 2001;60:916-923.

73 Lin WJ, Chang YF, Wang WL, Huang CY: Mitogen-stimulated TIS21 protein interacts with a protein-kinase- $\mathrm{C} \alpha$ - binding protein rPICK1. Biochem J 2001;354:635-643. 